\title{
Pharmacological activities of some triazinopyrazolothieno pyrimidine derivatives
}

\author{
SALEH A. BAHASHWAN \\ Taibah University \\ Faculty of Pharmacy \\ Department of Pharmacology and \\ Toxicology \\ Madinah Munawara, Saudi Arabia
}

Accepted April 4, 2017

Published online May 8, 2017

\begin{abstract}
Triazinopyrazolothieno pyrimidine derivatives $\mathbf{1 - 5}$ were evaluated for their anti-inflammatory, analgesic and anticancer activities and acute toxicity. Anti-inflammatory activity of the compounds was studied using the carrageenan test. All tested compounds showed analgesic activity, 3-methoxycarbonyl-4,6-dimethyl-8-[(N-methylindolyl)methyl] pyrimido $\left[5^{\prime}, 4^{\prime}: 4,5\right]$ thieno $\left[3^{\prime}, 2^{\prime}-3,4\right]$ pyrazolo $[5,1-c]$ triazine (4) showed activity comparable to that of diclofenac. Compounds 1-5 were also screened for anticancer activity on a human lung cancer cell line (A549) and a human prostate cancer cell line (DU145) using the MTT micro-cultured tetrazolium assay method. Compound 4 showed also significant anticancer activity against both cancer cell lines, comparable to that of doxorubicin. The most active compounds were tested for their acute toxicity and median lethal doses were evaluated.
\end{abstract}

Keywords: pyrimidine derivatives, triazinopyrazolothieno, anti-inflammatory, analgesic, anticancer, acute toxicity

Investigations of some triazinopyrazolothieno pyrimidine derivatives and their biological activities have gained great importance in recent years. Pyrazolopyrimidine derivatives showed the most pronounced activity against Mycobacterium tuberculosis comparable to that of the first line anti-tubercular drug isoniazid (1). Pyrimidine compounds showed an indirect anti-angiogenic effect through suppression of the secretion of VEGF and TGF-b1 from prostate cancer cells (2) and have, among others, been evaluated as cGMP phosphodiesterase inhibitors, but also as kinase inhibitors and potential anti-cancer agents (3). Pyrimidine derivatives were also found to have anti-inflammatory activity in BALB/c mice with locally induced edema (4). Pyridopyrimidine derivatives were recognized for their anticonvulsant and antidepressant activities but showed no neurotoxicity (5). Some of pyrimidine derivatives showed in vitro antiplasmodial activity against chloroquine-resistant (CQR) (K1) and drug-sensitive CQS (3D7) strains of Plasmodium falciparum (6). Also, pyrimidine derivatives showed good analgesic activity when compared to the standard

\footnotetext{
*Correspondence; e-mail: drsalehbahashwan@gmail.com
} 
drug pentazocine (7). Thioxopyrimidine derivatives showed good antifungal activity when screened in vitro against Candida albicans, Penicillium ssp. and Aspergillus niger, using the agar well disk diffusion method and using amphotericin-B as standard drug (8). Pyrazolopyrimidine and pyrimidine derivatives showed good antifungal activity when screened against C. albicans, Aspergillus fumigatus, Geotrichum candidum, Syncephalastrum racemosum. Also, pyrimidine derivatives exhibited significant activity against bacteria and the results were comparable with the standard control (9). New, poly-fused ring pyrazolothieno-pyrimidine derivatives showed good anti-parkinsonian, hypoglycemic and antimicrobial activities (10). Moreover, some new polycyclic triazolopyrazolo-pyridazine derivatives showed pharmacological activity (11). Herein, some triazinopyrazolothieno pyrimidine derivatives were tested for their acute toxicity, anti-inflammatory, analgesic and anticancer activities.

\section{EXPERIMENTAL}

\section{Chemistry}

Triazinopyrazolothieno pyrimidine derivatives $\mathbf{1}-\mathbf{5}$ (Fig. 1 ) were synthesized according to the reported methods (10). 3-Acetyl-4,6-dimethyl-8-[( $N$-methylindolyl)methyl]pyrimido $\left[5^{\prime}, 4^{\prime}: 4,5\right]$ thieno[ $\left.3^{\prime}, 2^{\prime}-3,4\right]$ pyrazolo[5,1-c]triazine (1), 3,6-dimethyl-8-[(N-methylindolyl)methyl]pyrimido $\left[5^{\prime}, 4^{\prime}: 4,5\right]$ thieno $\left[3^{\prime}, 2^{\prime}-3,4\right]$ pyrazolo[5,1-c]triazin-4-ol 6-methyl-8-[(N-methylindolyl)methyl]pyrimido $\left[5^{\prime}, 4^{\prime}: 4,5\right]$ thieno $\left[3^{\prime}, 2^{\prime}-3,4\right]$ pyrazolo[5,1-c]triazin-3-carbonitrile-4-ol (3), 3-methoxycarbonyl-4,6-dimethyl-8-[( $N$-methylindolyl)methyl] pyrimido $\left[5^{\prime}, 4^{\prime}: 4,5\right]$ thieno[ $\left.3^{\prime}, 2^{\prime}-3,4\right]$ pyrazolo[5,1-c]triazine(4) and 4-amino-6-methyl-8-[(Nmethylindolyl)methyl]pyrimido[ $\left.5^{\prime}, 4^{\prime}: 4,5\right]$ thieno $\left[3^{\prime}, 2^{\prime}-3,4\right]$ pyrazolo[5,1-c]triazine-3-carbonitrile (5) were afforded by the reaction of the 3-diazopyrazolothienopyrimidine derivative with the active reagent, namely, acetyl acetone, ethyl acetoacetate, ethyl cyanoacetate, di-

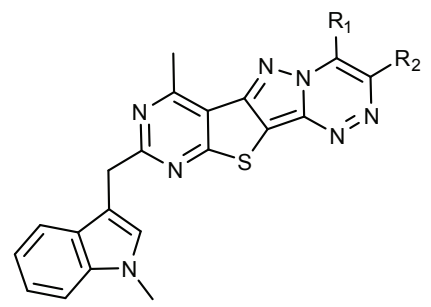

\begin{tabular}{cll}
\hline Compd. & $\mathrm{R}_{2}$ & $\mathrm{R}_{1}$ \\
\hline 1 & $-\mathrm{COCH}_{3}$ & $-\mathrm{CH}_{3}$ \\
2 & $-\mathrm{CH}_{3}$ & $-\mathrm{OH}$ \\
3 & $-\mathrm{CN}$ & $-\mathrm{OH}$ \\
4 & $-\mathrm{COOCH}_{3}$ & $-\mathrm{CH}_{3}$ \\
5 & $-\mathrm{CN}$ & $-\mathrm{NH}_{2}$ \\
\hline
\end{tabular}

Fig. 1. Structures of compounds 1-5. 
ethyl malonate and/or malononitrile, respectively, in the presence of sodium acetate as basic medium. Compounds $\mathbf{1 - 5}$ were evaluated for anti-inflammatory, analgesic and anticancer activities.

\section{Animals}

One hundred and fifty-six male and female Swiss albino mice, five to six weeks old and weighing 16-18 g, were obtained from the animal house of Taibah University (Madinah Munawara, KSA) in collaboration with King Saudi University (Riyadh, KSA). Experiments were approved by the Animal Ethical Committee of Taibah University. The animals were maintained according to the accepted standards of animal care.

\section{Anti-inflammatory evaluation}

Tested triazinopyrazolothieno pyrimidine derivatives 1-5 were dissolved in $0.5 \%$ carboxymethyl cellulose (CMC) solution and administered intraperitoneally (i.p.). Ninetysix mice were divided into sixteen groups, each group consisting of six animals. Edema was induced in the right hind paw of all mice by subcutaneous injection of $0.1 \mathrm{~mL}$ of $1.0 \%$ $(\mathrm{m} / \mathrm{V})$ carrageenan in $10 \%$ formal saline $(0.85 \% \mathrm{NaCl}$ in $10 \%$ formalin). The first group was kept as a control and was given the respective volume of the solvent $(0.5 \mathrm{~mL} 10 \%$ formal saline). Groups 2-15 were orally administered aqueous suspension of the tested compounds in doses of $5 \mathrm{mg} \mathrm{kg}^{-1} 1 \mathrm{~h}$ before carrageenan injection. The last group was administered diclofenac sodium (reference drug) in a dose of $5 \mathrm{mg} \mathrm{kg}^{-1}$, orally as aqueous suspension. The right paw volume was measured using a digital plethysmometer, directly before and 1, 2 and $3 \mathrm{~h}$ after administration of the tested compounds $(11,12)$.

\section{Analgesic activity}

Sixty mice were divided into 10 groups, one group was kept as a control (received saline), the second group received the vehicle (gum acacia), and the third received diclofenac sodium as a reference drug, whereas the other groups received compounds 1-5 via subcutaneous administration. The mice were dropped gently into a dry glass beaker of 1 $\mathrm{dm}^{3}$ capacity maintained at 55 to $55.5^{\circ} \mathrm{C}$ (13). Normal reaction time in seconds for all animals was determined at time intervals of 30,60 and $90 \mathrm{~min}$. The reaction time is defined as the time that elapses from the moment when the mouse reaches the hot beaker till the animal licks its feet or jumps out of the beaker (dose $5 \mathrm{mg} \mathrm{kg}^{-1}$ ). Relative potencies versus diclofenac sodium were determined.

\section{Anticancer activity}

Test compounds 1-5 were screened for anticancer activity on a human lung cancer cell line (A549) and a human prostate cancer cell line (DU145) using the MTT micro-cultured tetrazolium assay method (14). Doxorubicin was used as the reference drug. Cells were harvested from the logarithmic phase cultures and re-suspended in Dulbecco's modified Eagle's medium supplemented with $10 \%$ fetal bovine serum. Cell counts were adjusted and equal numbers of cells were plated in each well of 96-well culture plates and allowed to grow overnight at $37^{\circ} \mathrm{C}$ in the presence of $5 \% \mathrm{CO}_{2}$. The cells were treated with test sub- 
stances at various concentrations for 72 hours. In vehicle control culture wells, a maximum of $0.5 \%$ DMSO saturated with $\mathrm{CO}_{2}$ was added. Fresh culture medium supplemented with test substances was renewed every 24 hours. Thereafter, $0.5 \mathrm{mg} \mathrm{mL}^{-1}$ of MTT reagent was added to each well and the micro plate was incubated for further 4 hours at $37^{\circ} \mathrm{C}$ in the presence of $5 \% \mathrm{CO}_{2}$. Finally, the cells were solubilized by adding a solubilizing solution and allowed to incubate at $37^{\circ} \mathrm{C}$ overnight. After complete solubilization of formazan crystals, the absorbance was read at $540 \mathrm{~nm}$ in a micro plate reader (Bio-Rad, USA). The results obtained from quadruplicate wells were used to calculate $I C_{50}$ of the test compounds.

\section{Acute toxicity}

Median lethal doses $\left(L D_{50}\right)$ of the most active compounds 2 and 4 were determined in mice (15). Groups of male mice, each of six animals, were injected i.p. with graded doses of each of the test compounds. The percentage of mortality in each group of animals was determined $24 \mathrm{~h}$ after injection. Computation of $L D_{50}$ was processed by a graphical method.

\section{Statistical analysis}

Assay results are shown as the mean \pm standard error of the mean (SEM). Statistical analyses were carried out using the Sigma Plot software (SPSS Inc., Chicago, USA). Oneway analysis of variance (ANOVA) followed by Tukey's post-hoc test was used to assess the presence of significant differences. Differences were considered statistically significant at $p \leq 0.05$.

\section{RESULTS AND DISCUSSION}

\section{Anti-inflammatory activity}

Anti-inflammatory studies after 1, 2 and $3 \mathrm{~h}$ showed the same trend of activity of the five triazinopyrazolothieno pyrimidine compounds $\mathbf{1 - 5}$ but also revealed different activity

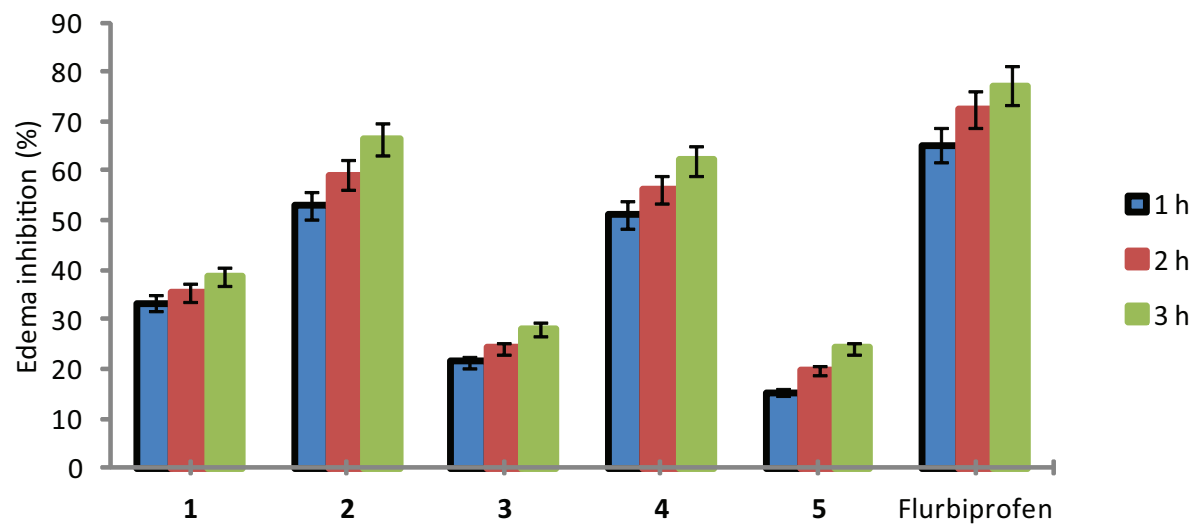

Fig. 2. Anti-inflammatory activity of compounds $1-5$ (dose $5 \mathrm{mg} \mathrm{kg}^{-1} \mathrm{~b} . \mathrm{m}$, p.o.). Mean $\pm \mathrm{SEM}, n=6$. 
of each of them. After $1 \mathrm{~h}$, compounds 3 and 5 showed weak anti-inflammatory activity (21.4 \pm 1.3 and $15.2 \pm 1.1 \%$, resp.), compound 1 showed moderate anti-inflammatory activity (33.2 $\pm 1.3 \%)$ and compounds 2 and 4 showed strong anti-inflammatory activity (53.1 \pm 1.2 and $51.2 \pm 1.4 \%$ ) in comparison with flurbiprofen ( $65.3 \pm 1.3 \%$ ). After $2 \mathrm{~h}$, compounds 3 and 5 still showed weak anti-inflammatory activity (24.2 \pm 1.2 and $19.6 \pm 1.2 \%$, resp.), compound $\mathbf{1}$ moderate activity ( $35.4 \pm 1.3 \%$ ) but compounds 2 and 4 possessed strong anti-inflammatory activity $(59.2 \pm 1.5$ and $56.3 \pm 1.4 \%)$ compared to the standard drug $(72.6 \pm 1.1 \%)$. Accordingly, after $3 \mathrm{~h}$ compounds 3 and 5 decreased paw edema by $28.2 \pm 1.2$ and $24.3 \pm 1.1 \%$, compound 1 by $38.7 \pm 1.1 \%$, while compounds 2 and 4 showed the most pronounced reduction of paw inflammation $(66.5 \pm 1.3$ and $62.1 \pm 1.2 \%)$ in comparison with the standard drug flurbiprofen (77.3 $\pm 1.4 \%$ ) (Fig. 2).

\section{Analgesic activity}

Activity of all compounds was normalized relative to the standard drug diclofenac sodium with arbitrary unit activity $(1.00 \pm 0.02)$ and expressed as a respective ratio. Compounds 1-5 differed in analgesic activity although the same trend of activity increasing with time was observed for each of them (Fig. 3). After $30 \mathrm{~min}$, compounds 3 and 5 exerted weak $(0.35 \pm 0.01$ and $0.21 \pm 0.01)$, compounds 1 and 2 moderate $(0.61 \pm 0.01$ and $0.62 \pm 0.02)$ and compound 4 strong analgesic activity $(0.82 \pm 0.03)$ After $60 \mathrm{~min}$, compounds 3 and 5 still showed weak $(0.39 \pm 0.02$ and $0.25 \pm 0.01)$, compounds 1 and 2 moderate (both $0.65 \pm$ $0.01)$ and compound 4 strong analgesic activity $(0.83 \pm 0.03)$. After $90 \mathrm{~min}$, compounds 3 and 5 showed weak $(0.43 \pm 0.02$ and $0.31 \pm 0.03)$, compounds 1 and 2 moderate $(0.69 \pm 0.02$ and $0.67 \pm 0.03)$, while compound 4 showed strong analgesic activity $(0.88 \pm 0.01)$. After 120 min, compound 5 still showed weak $(0.34 \pm 0.02)$, compound 3 moderate $(0.46 \pm 0.02)$, compounds 1 and 2 strong analgesic activity $(0.73 \pm 0.03$ and $0.71 \pm 0.01)$, and compound 4 even higher analgesic activity $(0.92 \pm 0.01)$ comparable to that of diclofenac.

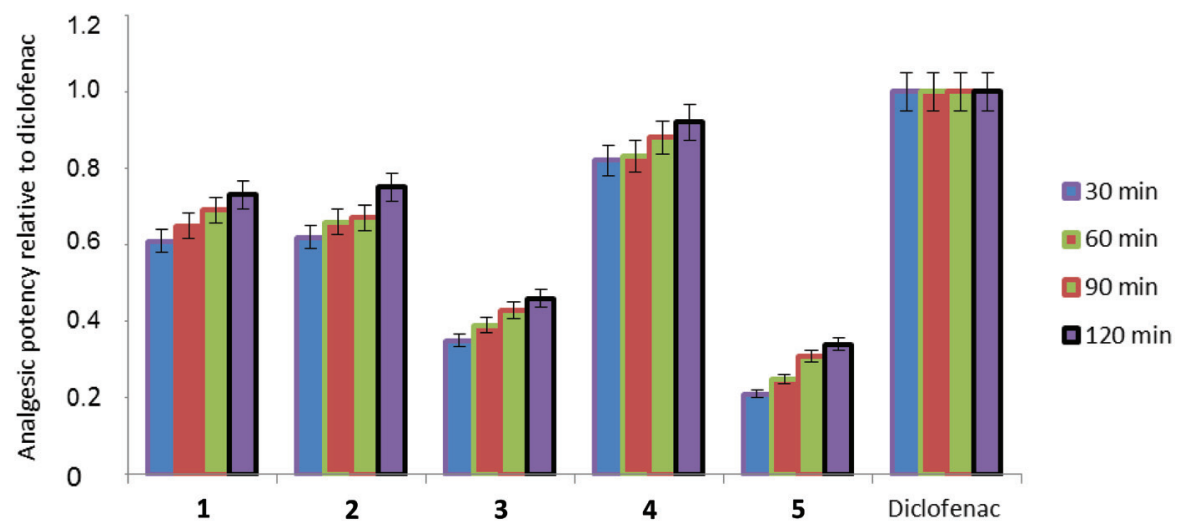

Fig. 3. Analgesic activity of the tested compounds $1-5$ relative to diclofenac (dose $5 \mathrm{mg} \mathrm{kg}^{-1}$ b.m, p.o.). Mean \pm SEM, $n=6$. All results were significantly different $(p \leq 0.05)$ from the standard (diclofenac) and normal control (10 \% formal saline) (Tukey's post-hoc test). 


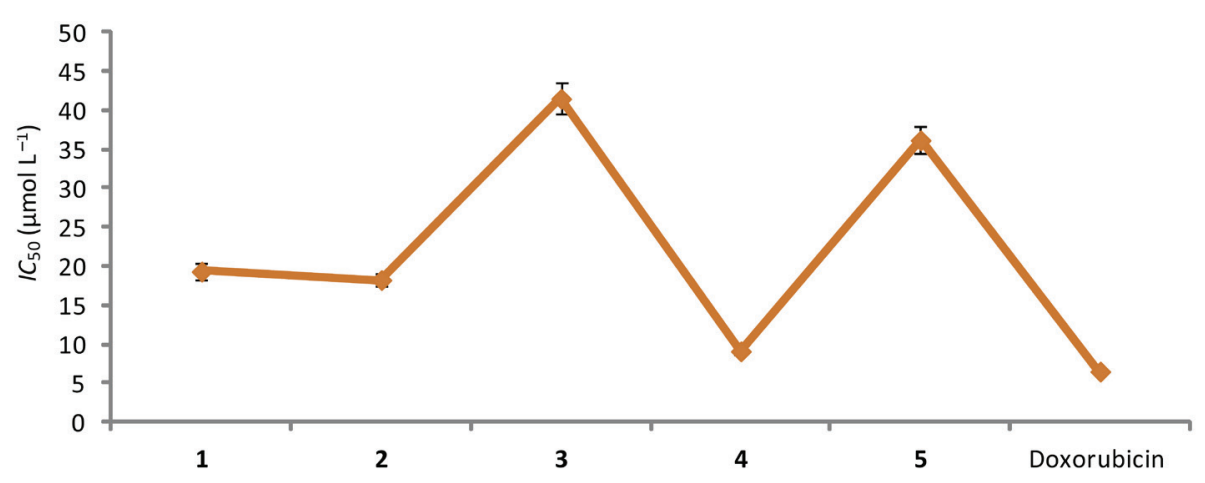

Fig. 4. $I C_{50}$ values of compounds $\mathbf{1 - 5}$ against the human lung cancer cell line (A549). Mean $\pm \mathrm{SEM}, n=6$.

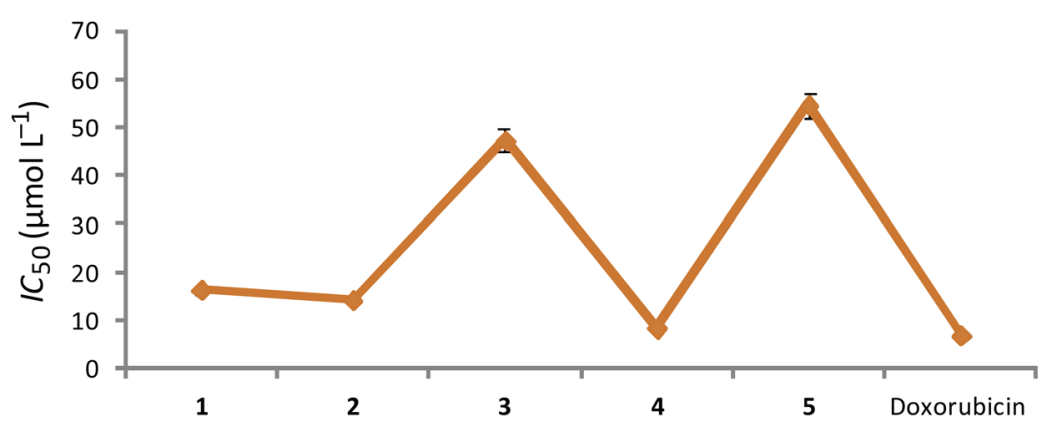

Fig. 5. $I C_{50}$ values of compounds $\mathbf{1}-\mathbf{5}$ against the human prostate cancer cell line (DU145). Mean \pm SEM, $n=6$.

\section{Anticancer activity}

Some of the tested compounds showed significant anticancer activity against the human lung cancer cell line (A549) and the human prostate cancer cell line (DU145) (Figs. 4 and 5).

It is evident from Fig. 4 that compound 4 showed the highest activity against the human lung cancer cell line with $I C_{50}$ of $9.11 \mu \mathrm{mol} \mathrm{L}-1$, compounds 1 and 2 were found to be moderately effective (19.34 and $18.26 \mu \mathrm{mol} \mathrm{L}^{-1}$ ) whereas compounds 3 and $\mathbf{5}$ were the least effective $\left(41.51\right.$ and $\left.36.19 \mu \mathrm{mol} \mathrm{L}^{-1}\right)$ in comparison with the standard drug doxorubicin $\left.(6.52 \mu \mathrm{mol} \mathrm{L})^{-1}\right)$.

It is clear from Fig. 5 that the highest activity against the human prostate cancer cell line with the $I C_{50}$ value of $8.42 \mu \mathrm{mol} \mathrm{L}^{-1}$ was shown by compound 4, whereas compounds 1 and 2 were found to be moderately effective $\left(16.28\right.$ and $\left.14.17 \mu \mathrm{mol} \mathrm{L}^{-1}\right)$ and compounds 3 and 5 weakly effective $\left(47.25\right.$ and $\left.54.61 \mu \mathrm{mol} \mathrm{L}{ }^{-1}\right)$ in comparison with doxorubicin $\left(6.87 \mu \mathrm{mol} \mathrm{L}^{-1}\right)$. 
Table I. Acute toxicity of selected compounds

\begin{tabular}{cc}
\hline Compound & $\left.L D_{50}(\mu \mathrm{mol} \mathrm{kg})^{-1}\right)^{\mathrm{a}}$ \\
\hline 2 & $4.57 \pm 0.03$ \\
4 & $5.68 \pm 0.03$ \\
Flurbiprofen & $5.32 \pm 0.06$ \\
\hline
\end{tabular}

a Values represent the mean $\pm \mathrm{SEM}, n=6$.

\section{Structure activity relationship}

Compounds 2 and 4 showed the highest anti-inflammatory activity. This is probably due to the presence of hydroxyl-triazinopyrazolo moiety in compound $\mathbf{2}$ and methoxycarbonyl-triazinopyrazolo moiety in compound 4 . The latter might also be responsible for the highest analgesic and anticancer activity of compound 4.

\section{Acute toxicity}

The most active compounds were tested for acute toxicity. $L D_{50}$ of compounds 2 and 4 was 4.57 and $5.68 \mu \mathrm{mol} \mathrm{kg}{ }^{-1} \mathrm{bm}$, resp., whereas that of flurbiprofen was $5.32 \mu \mathrm{mol} \mathrm{kg} \mathrm{kg}^{-1}$ (i.p.) (Table I). These $L D_{50}$ values indicate comparable safety of compounds 2 and 4 to that of flurbiprofen.

\section{CONCLUSIONS}

In the present investigation, five triazinopyrazolothieno pyrimidine derivatives $\mathbf{1 - 5}$ were screened for their anti-inflammatory, analgesic and anticancer activity. Compound 4 with an ester functional group showed the strongest anti-inflammatory and analgesic activity, comparable to that of diclofenac. The same compounds exerted the highest antiproliferative activity against the human lung cancer cell line (A549) and the human prostate cancer cell line (DU145), similar to that of the standard drug doxorubicin. The other tested compounds exhibited low or moderate activities.

Acknowledgements. - The author acknowledges Dr. Ahmed A. Fayed, Taibah University, Madinah Munawara, Saudi Arabia, for providing the tested compounds. Also, the author acknowledges the College of Pharmacy, King Saudi University, for collaboration and support to animals

\section{REFERENCES}

1. A. B. Siddiqui, A. R. Trivedi, V. B. Kataria and V. H. Shah, 4,5-Dihydro-1H-pyrazolo[3,4- $d]$ pyrimidine containing phenothiazines as antitubercular agents, Bioorg. Med. Chem. Lett. 51 (2014) 14931495; DOI: 10.1016/j.bmcl.2014.02.012.

2. N. M. Y. Elsayed, D. A. Abou El Ella, R. A. T. Serya, M. F. Tolba, R. Shalaby and K. A. M. Abouzid, Design, synthesis and biological evaluation of indazole-pyrimidine based derivatives as antican- 
cer agents with anti-angiogenic and antiproliferative activities, Med. Chem. Commun. 7 (2016) 881-899; DOI: 10.1039/C5MD00602C.

3. A. K. Verma, R. Kumari, A. K. Sing, B. B. Sharma, A. Martin and R. Kant, Synthesis characterization and anticancer activity of novel $\mathrm{N}$-(sugar pyranosyl)thienopyrimidine 4 -amine derivatives, Int. Res. J. Pharm. 5 (2014) 922-925; DOI: 10.7897/2230-8407.0512187.

4. S. Kumaresan, S. Chandrasekaran, K. M. Sakthivel, C. Guruvayoorappan and V. M. Israel, Synthesis, characterization and anti-inflammatory activity of some novel pyrimidin-2-amines on carrageenan-induced paw edema in balb/c mice, J. Chem. Pharm. Res. 6 (2014) 593-606.

5. H. J. Zhang, S. B. Wang, X. Wen, J. Z. Li and Z. S. Quan, Design, synthesis, and evaluation of the anticonvulsant and antidepressant activities of pyrido[2,3- $d$ ]pyrimidine derivatives, Med. Chem. Res. 25 (2016) 1287-1298; DOI: 10.1007/s00044-016-1559-1.

6. K. Singh, H. Kaur, K. Chibale, J. Balzarini, S. Little and P. V. Bharatam, 2-Aminopyrimidine based 4-aminoquinoline anti-plasmodial agents. Synthesis, biological activity, structure-activity relationship and mode of action studies, Eur. J. Med. Chem. 52 (2012) 82-97; DOI: 10.1016/j.ejmech.2012.03.007.

7. A. A. Abu-Hashem and M. M. Youssef, Synthesis of new visnagen and khellin furochromone pyrimidine derivatives and their anti-inflammatory and analgesic activity, Molecules 16 (2011) 1956-1972; DOI: 10.3390/molecules16031956.

8. P. Rathee, R. K. Tonk, A. Dalal, M. K. Ruhil and A. Kumar, Synthesis and application of thiobarbituric acid derivatives as antifungal agents, Cell. Mol. Biol. 62 (2016) 5 pages; DOI: 10.4172/1165158X.1000141.

9. D. Cai, Z.-H. Zhang, Y. Chen, X.-J. Yan, S.-T. Zhang, L.-J. Zou, L.-H. Meng, F. Li and B.-J. Fu, Synthesis of some new thiazolo[3,2-a]pyrimidine derivatives and screening of their in vitro antibacterial and antitubercular activities, Med. Chem. Res. 25 (2016) 292-302; DOI: 10.1007/s00044-0151481-y.

10. N. O. Al-Harbi, S. A. Bahashwan, A. A. Fayed, M. S. Aboonq, A. El-Galil and E. Amr, Anti-parkinsonism, hypoglycemic and anti-microbial activities of new poly fused ring heterocyclic candidates, Int. J. Biol. Macromol. 57 (2013) 165-173; DOI: 10.1016/j.ijbiomac.2013.03.019.

11. S. A. Bahashwan, N. O. Al-Harbi, A. Fayed, A. El-Galil E. Amr, K. Shadid, A. M. Alalawi and I. M. S. Bassati, Pharmacological activities of some new polycyclic triazolopyrazolopyridazine derivatives, Int. J. Biol. Macromol. 51 (2012) 7-17; DOI: 10.1016/j.ijbiom,ac.2012.05.002.

12. S. A. Bahashwan, A. A. Fayed, A. El-Galil E. Amr, E. M. Flefel and A. Kalmouch, Synthesis and pharmacological activities of some new triazolo- and tetrazolopyrimidine derivatives, Molecules 18 (2013) 15051-15063; DOI: 10.3390/molecules181215051.

13. A. N. O. Al-Harbi, S. A. Bahashwan, A. A. Fayed and M. A. Ramadan, Pharmacological activities evaluation of some new pyrazolo-pyrimidino-pyridazine derivatives, Afr. J. Pharm. Pharmacol. 7 (2013) 517-523; DOI: 10.5897/AJPPX12.003.

14. A. L. A. Lima, A. F. Alves, A. L. Xavier, T. Mozzini-Monteiro, T. R. R. Oliveira, F. C. Leite, M. H. Shih and F. Y. Ke, Syntheses and evaluation of antioxidant activity of sydnonyl substituted thiazolidinone and thiazoline derivatives, Bioorg. Med. Chem. 12 (2004) 4633-4643; DOI: 10.1016/j. bmc.2004.06.033.

15. W. N. Matias, M. M. V. S. C. Branco, M. F. V. Souza and M. R. Piuvezam, Anti-inflammatory activity and acute toxicity studies of hydroalcoholic extract of Herissantia tiubae, Bras. J. Pharmacogn. 26 (2016) 225-232; DOI: 10.1016/j.bjp.2015.11.001. 